\title{
Extended transduodenal sphincteroplasty for bile duct stones associated with a periampullary diverticulum
}

\author{
Musa Akoglu', Burhan Sahin² and Brian R. Davidson ${ }^{3}$
}

Departments of ${ }^{1}$ Gastrointestinal Surgery and ${ }^{2}$ Gastroenterology, Turkey Advanced Specialization
Hospital, Ankara, Turkey, and the ${ }^{3}$ Department of Surgery, Royal Free Hospital and School of Medicine,
Pond Street, London NW3 $2 Q G, U K$

Summary: Extended transduodenal sphincteroplasty has been suggested as an alternative to choledochoduodenostomy for the surgical management of bile duct stones associated with a periampullary diverticulum but its value has not previously been investigated. Over a 3 year period, nine patients underwent extended transduodenal sphincteroplasty for common bile duct calculi associated with a periampullary diverticulum with no operative or post-operative mortality and minimal morbidity. Follow-up ranging from 20 to 60 months has shown remission of pain in all but one patient, who has had a normal endoscopic cholangiogram and no further episodes of jaundice or cholangitis. Extended transduodenal sphincteroplasty is a safe and effective alternative to choledochoduodenostomy for the surgical management of choledocholithiasis associated with a periampullary diverticulum.

\section{Introduction}

The prevalence of periampullary diverticula has been reported as $12.5 \%$ from a large retrospective analysis of patients undergoing endoscopic retrograde cholangiopancreatography $(\mathrm{ERCP})^{1}$ whereas in a smaller prospective study $25 \%$ of patients undergoing ERCP were found to have duodenal diverticula of which $90 \%$ were located close to the ampulla of Vater. ${ }^{2}$ Although the majority of these diverticula cause no symptoms, the presence of a periampullary diverticulum (PAD) predisposes to the development of bile duct stones. ${ }^{3}$ Following cholecystectomy an $85 \%$ incidence of recurrent stones has been reported in patients with periampullary diverticula. ${ }^{3}$ The reason for this high incidence of bile duct stones has not been established, although external compression of the biliary tree by the diverticulum has been implicated and sphincter dysfunction ${ }^{4}$ and abnormal bacterial colonization $^{5}$ are frequently found.

To prevent recurrent stone formation the diverticulum may be resected (diverticulectomy), the sphincter of Oddi divided (endoscopically or surgically) or a biliary-enteric anastomosis performed, for example, choledochoduodenostomy. Alternatively an extended transduodenal sphincteroplasty (ETDS) may be performed, a technique which has previously been described and a successful out-

Correspondence: B.R. Davidson, M.D., F.R.C.S. Accepted: 9 December 1991 come reported in a single case. ${ }^{6}$ This procedure, by providing drainage of both the biliary tree and the diverticulum, may be preferable to carrying out biliary-enteric anastomosis. The role of ETDS i patients with choledocholithiasis and a periamput? lary diverticulum was therefore investigated.

\section{Patients}

Over the period January 1985 to June 1988 , nine of the patients who were referred to the Department of Surgery at the Turkey Advanced Specialization Hospital with biliary tract obstruction due to stones were found at the time of endoscopic cholangiography to have a paravaterian diverticulum. There were three males and six females with a median age of 58 years (range 47-67). All presented with upper abdominal pain. Eight were clinically jaundiced on admission and the other gave a history of jaundice which had resolved prior to admission. Four patients had had a cholecystectomy $2-7$ years previously, one along with exploration of the common bile duct and removal of stones. None of the patients had major medical problems although one was an insulin-dependent diabetic.

\section{Investigations}

In all but one patient the liver function tests showed the typical picture of obstructive jaundice with an 
elevated bilirubin and alkaline phosphatase. The patient whose jaundice had resolved prior to admission showed an elevated alkaline phosphatase alone. Ultrasonography demonstrated gallbladder stones in those patients who had not previously undergone cholecystectomy and a dilated biliary tree in all nine patients (common bile duct diameter 11-19 mm). Stones were detected within the bile duct in eight patients. In the remaining patient jaundice had resolved prior to admission and the common bile duct (CBD) diameter was $11 \mathrm{~mm}$. Endoscopic retrograde cholangiopancreatography (ERCP) had been attempted in all patients, with paravaterian diverticula being found at the one, six (four cases), seven, eight and 120 'clock positions along with one case of a central diverticulum. An endoscopic cholangiogram was obtained in five of the nine patients $(56 \%)$ and CBD stones were demonstrated in all five. Two of the nine patients were referred for surgery following a failed attempt at endoscopic stone removal whereas in the other seven endoscopic clearance of the CBD was not attempted.

\section{Surgery}

The technique of extended transduodenal sphincteroplasty was as follows. The abdomen was opened through a right upper paramedian incision. If present, the gallbladder was removed and the common bile duct explored through a $2-3 \mathrm{~cm}$ longitudinal choledochotomy. After removal of any stones from the CBD a soft catheter was passed along the duct until it passed through the ampulla and was palpated through the wall of the duodenum. A $4 \mathrm{~cm}$ oblique duodenostomy allowed good visualization of the ampulla and the adjacent diverticulum. A sphincteroplasty was performed over the catheter for at least $1.5 \mathrm{~cm}$ with excision of the bridge between the diverticulum and the ampulla. The sphincteroplasty was sutured with interrupted $3 / 0$ Vicryl. If the diverticulum was in the vicinity of the pancreatic duct this was also cannulated prior to sphincteroplasty and the septum between the common bile duct and pancreatic duct divided. The CBD was closed over a t-tube using interrupted 3/0 Vicryl and the duodenotomy closed with $3 / 0$ Vicryl.

\section{Results}

At operation stones were found within the common bile duct in eight of the nine patients, all of which had been demonstrated on pre-operative imaging. Cholecystectomy was performed in all patients with gallbladder in situ, all of which contained stones. No operative difficulties were encountered in carrying out the extended transduodenal sphincteroplasty. There were no operative or peri-operative mortalities. The only morbidity was one patient who had an external bile leak following removal of the t-tube one week after surgery. The patient remained well and the leak closed spontaneously after a further week. The patients have been followed with clinical examination and biochemical screening for a period ranging from 20 to 60 months. Eight of the nine patients are now asymptomatic and all have normal liver function tests. One patient has persistent back pain, also present pre-operatively, and underwent an ERCP which showed a normal post-sphincteroplasty appearance.

\section{Discussion}

The present study has shown that an extended transduodenal sphincteroplasty can be safely performed in patients with bile duct stones associated with a periampullary diverticulum. This supports the previous report by Kaminsky. ${ }^{6}$ A longer followup period is obviously required to exclude the possibility of late complications but the results of the short and intermediate follow-up are very satisfactory.

Only one of the patients in this series had previously undergone exploration of the common bile duct and removal of calculi. This contrasts with the practice of many surgeons who would carry out clearance of the biliary tree at a first operation and only consider the management of the PAD if bile duct stones were to recur. ${ }^{6}$ However, the reported very high incidence of recurrent common bile duct stones in this group of patients ${ }^{3}$ would suggest that the primary procedure should also be definitive for two reasons. Firstly, if recurrent bile duct stones were to form, endoscopic removal may not be possible when a PAD is present and, secondly, surgery for recurrent stones is associated with a significantly higher morbidity and mortality than a primary procedure. $^{7}$

It should not be concluded from the present study, however, that all patients with choledocholithiasis and PAD should be treated by ETDS. Although there were no mortalities and no significant morbidity in the present study, previously published series of sphincteroplasty have shown a complication rate varying from 0 to $10 \%{ }^{8-10}$ and a mortality of 0 to $7 \% .^{8-10}$ The results from different centres vary widely and perhaps more informative than the results from specialized centres are those obtained from many surgeons within a region. This suggests that the overall mortality of ETDS may be $5 \%$ and the morbidity over $30 \% .{ }^{11}$ The lack of mortality and minimal morbidity found in the present study may be attributed to all operations 
being performed by experienced surgeons within a specialized centre and secondly that only patients considered to be 'fit for surgery' were included. Patients who were elderly, with significant medical problems or who had presented with cholangitis were treated by endoscopic sphincterotomy (ES).

The value of endoscopic sphincterotomy for the removal of CBD stones is well established, especially in patients at high operative risk, with less than $20 \%$ subsequently developing symptoms necessitating cholecystectomy. ${ }^{12-14}$ However, the optimum management of patients with CBD stones associated with a PAD is more controversial than the situation for CBD stones alone. Although the presence of a PAD was at one time considered to be an absolute contraindication to endoscopic sphincterotomy ${ }^{15}$ and a lower success rate for cannulating the ampulla has been reported ${ }^{16}$ the recent results from major centres in patients with diverticula have been similar to those in patients without diverticula. ${ }^{17,18}$ It would seem likely, therefore, that endoscopic sphincterotomy is the treatment of choice in patients with choledocholithiasis associated with a periampullary diverticulum who are elderly, have major medical problems or who have had previous cholecystectomy. The optimum management of fit patients with choledocholithiasis associated with a PAD in whom the gallbladder is in situ has yet to be established.

The main surgical options are bile duct clearance alone or along with choledochoduodenostomy, diverticulectomy or transduodenal sphinctero-

\section{References}

1. Vaira, D., Dowsett, J.F., Hatfield, A.R.W. et al. Is duodenal diverticulum a risk factor for sphincterotomy? Gut 1989, 30: 939-942.

2. Osnes, M., Lotveit, T., Larsen, S. \& Aune, S. Duodenal diverticula and their relationship to age, sex and biliary calculi. Scand J Gastroenterol 1981, 16: 103-107.

3. Lotveit, T., Osnes, M. \& Larsen, S. Recurrent biliary calculi. Duodenal diverticula as a predisposing factor. Ann Surg 1982, 196: 30-32.

4. Viceconte, G., Viceconte, G. \& Bogliolo, G. Endoscopic manometry of the sphincter of Oddi in patients with and without juxtapapillary duodenal diverticula. Scand J Gastroenterol 1984, 19: 329-333.

5. Skar, A.G., Skar, V., Myren, J. \& Osnes, M. Bacterial growth in the region of the papilla of Vater in patients with and without duodenal diverticula. Scand J Gastroenterol 1986, 21 (Suppl 120): 19.

6. Kaminsky, H.H., Thompson, W.R. \& Davis, B. Extended sphincteroplasty for juxtapapillary duodenal diverticulum. Surg Gyn Obstet 1986, 162: 280-281.

7. McSherry, C.K. \& Glenn, F. The incidence and causes of death following surgery for non-malignant biliary tract disease. Ann Surg 1980, 191: 271-275.

8. Rutledge, R.H. Sphincteroplasy and choledochoduodenostomy for benign biliary obstructions. Ann Surg 1976, 183: 476-487. plasty. Clearance of the bile duct alone in patients with PAD is associated with a high rate of recurrent stones $^{3}$ whilst diverticulectomy may be technically difficult and associated with a high operative morbidity. ${ }^{19,20}$ Both TDS and choledochoduodenostomy are suitable means of preventing further choledocholithiasis and are associated with similar operative morbidity and mortality. "Which technique is used may be based on technical factors, choledochoduodenostomy being more easily performed if the CBD is markedly dilated. ETDS may be preferable if there is no duct dilatation due to pre-operative nasobiliary drainage, if a calculus is impacted at the ampulla or if an ampullary tumour is suspected at operation.

In conclusion this study has demonstrated that extended transduodenal sphincteroplasty may be carried out in patients with CBD stones associated with a PAD both safely and effectively. The early results would justify a prospective randomized study comparing endoscopic sphincterotomy or choledochoduodenostomy with extended transduodenal sphincteroplasty in patients with choledocholithiasis and a periampullary diverticulum who are considered 'fit for surgery'.

\section{Acknowledgement}

We should like to thank Professor K.E.F. Hobbs of th University Department of Surgery at the Royal Fre Hospital and School of Medicine, Pond Street, Hamp stead, London NW3 for his comments on this paper.

9. Austin Jones, S., Steedman, R.A., Keller, T.B. \& Smith, L.L. Transduodenal sphincteroplasty for biliary and pancreatic disease. Am J Surg 1969, 118: 292-306.

10. White, T.T. Indications for sphincteroplasty as opposed to choledochoduodenostomy. Am J Surg 1973, 126: 165-170.

11. Baker, A.R., Neoptolemos, J.P., Leese, T. \& Fossard, D.P. Choledochoduodenostomy, transduodenal sphincteroplasty and sphincterotomy for calculi for the common bile duct. Surg Gyn Obstet 1987, 164: 245-251.

12. Davidson, B.R., Neoptolemos, J.P. \& Carr-Locke, D.L. Endoscopic sphincterotomy for common bile duct calculi in patients with gall bladder in situ considered unfit for surgery. Gut 1988, 29: 114-120.

13. Hansell, D.T., Millar, M.A., Murray, W.R., Gray, G.R. \& Gillespie, G. Endoscopic sphincterotomy for bile duct stones in patients with intact gallbladders. Br J Surg 1989, 76: 856-858.

14. Martin, D.F. \& Tweedle, D.E.F. Endoscopic management of common duct stones without cholecystectomy. Br J Surg 1987, 74: 209-211.

15. Gliedman, M.L. \& Gold, M.S. Choledochoduodenostomy. In: Schwartz, S.I. \& Ellis, I.I. (eds) Maingot's Abdominal Operations, 9th ed. Connecticut, Prentice Hall International Inc, 1982. 
16. Vaira, D., Dowsett, J.F., Hatfield, A.R.W. et al. Is duodenal diverticulum a risk factor for sphincterotomy? Gut 1989, 30: 939-942.

17. Chi-Sin Chang-Chein. Do juxtapapillary diverticula of the duodenum interfere with cannulation at endoscopic retrograde cholangiopancreatography. Gastrointest Endosc 1987, 33: $298-300$.

18. Vaira, D., D'Anna, L., Ainley, C. et al. Endoscopic sphincterotomy in 1000 consecutive patients. Lancet 1989, ii: $431-434$.
19. Iida, F. Transduodenal diverticulectomy for periampullary diverticula. World J Surg 1979, 3: 103-106.

20. Thompson, N.W. Transduodenal diverticulectomy for periampullary diverticula. Invited commentary. World $J$ Surg 1979, 3: 135-136. 